\title{
IL13RA2 Positive
}

National Cancer Institute

\section{Source}

National Cancer Institute. IL13RA2 Positive. NCI Thesaurus. Code C134496.

An indication that IL13RA2 expression has been detected in a sample. 